\title{
RECOVERING PREHISTORIC WOODWORKING SKILLS USING SPATIAL ANALYSIS TECHNIQUES
}

\author{
Kristóf Kovács ${ }^{\mathrm{a}, \mathrm{b}} *$, Klaus Hanke ${ }^{\mathrm{a}}$ \\ ${ }^{a}$ Surveying and Geoinformation Unit, University of Innsbruck, Austria - (kristof.kovacs, klaus.hanke)@uibk.ac.at \\ ${ }^{\mathrm{b}}$ Institute of Geography, Georg-August-Universität Göttingen, Germany - kkovacs@ gwdg.de
}

KEY WORDS: Intangible Cultural Heritage, Woodworking Techniques, Woodworking Efficiency, Bronze Age, Axe and Adze, Tool Mark, Spatial Analysis, GIS

\begin{abstract}
:
Recovering of ancient woodworking skills can be achieved by the simultaneous documentation and analysis of the tangible evidences such as the geometry parameters of prehistoric hand tools or the fine morphological characteristics of well preserved wooden archaeological finds. During this study, altogether 10 different hand tool forms and over 60 hand tool impressions were investigated for the better understanding of the Bronze Age woodworking efficiency. Two archaeological experiments were also designed in this methodology and unknown prehistoric adzes could be reconstructed by the results of these studies and by the spatial analysis of the Bronze Age tool marks. Finally, the trimming efficiency of these objects were also implied and these woodworking skills could be quantified in the case of a Bronze Age wooden construction from Austria. The proposed GIS-based tool mark segmentation and comparison can offer an objective, user-independent technique for the related intangible heritage interpretations in the future.
\end{abstract}

\section{INTRODUCTION}

The establishment and the categorisation of Intangible Cultural Heritage (ICH) have been carried out by the United Nations Educational, Scientific and Cultural Organization (UNESCO) in 2003 (UNESCO, 2003). "Traditional craftsmanship" is one of the main ICH classes and some prehistoric woodworking techniques as the approximately 3000-year-old "Chinese traditional architectural craftsmanship for timber-framed structures" have been also listed by the UNESCO as intangible heritage of Humanity. Another appropriate ICH category should also be mentioned in this study as the "Woodcrafting knowledge of the Zafimaniry" in Madagascar is identified within the class of "Knowledge and practices concerning nature and the universe". The Zafimaniry community still lives in remote forested regions and they only use traditional wood sculpting methods for construction works and decorative functions. This is the reason why this heritage is declared as a broad and deep knowledge of the nature (Scovazzi, 2015).

The prehistoric societies were also strongly dependent on the ancient environment and some early records of forest use have revealed the fast development of specialized woodworking industries and the importance of the unique carpentry skills in the early Bronze Age (Johann et al., 2012). On the other hand, a spectacular Neolithic archaeological find, an around 7000-yearold wooden water well has unveiled the earliest known timbering techniques. These woodworking capabilities supported the foundation of settlement infrastructures that has also resulted the significant improvement of agricultural activities (Tegel et al., 2012). The relevance of prehistoric woodworking skills in the socio-cultural evolution has been stated by other archaeological studies as well. The investigation of ancient wooden houses (Coles, 2006) and the experimental construction of a Bronze-Age-type sewn-plank boat (Van de Noort et al., 2014) have also proved the particular know-how of the first carpenters.

The recovering and understanding of these forgotten skills is a challenging research task as the early human life can only be analysed by tangible evidences and an intangible heritage must be connected, in whatever form it takes, to the present (Stefano et al., 2012). In this study, the key tangible evidences are the well-preserved wooden objects and the intangible information can be precisely extracted and interpreted from these archaeological finds. The morphological characteristics of these tangible evidences such as tool marks or timber joining techniques can offer special opportunities for the understanding of the forgotten intangible heritage values. The spatial analysis of these morphological patterns provides novel theory about the assessment of Bronze Age woodworking efficiency. The goal of this paper is to discuss this idea by presenting the developed data collection and three-dimensional (3D) analysis methods, and the results of this innovative investigation workflow.

\section{RELATED WORKS}

There are two types of tangible evidences in the case of ancient woodworking: the hand tools such as Bronze Age axes or adzes and the previously suggested remarkable wooden finds.

The cutting edges of the metal hand tools are studied by traceology, the research of use-wear marks. The possible usage of these archaeological objects can be interpreted from these patterns. Unfortunately, there are several disadvantages of this technique as the corrosion, diversity of uses, regular sharpening and recycling have destructed most of these marks (Kienlin et al., 1998; Roberts et al., 2003). Only non-specific interpretation can be conducted by metal traceology such as the identification of the most used zones of a cutting edge. However, the level of usage can represent the social or even the ideological role of the artefacts as several prehistoric axes and adzes with very specific morphological characteristics have been discovered for example in funerary contexts (Sáez et al., 2015).

In another research interest, the woodworking efficiency of different materials, for instance experimental archaeologists compare stone and metal axes. The concrete morphological evidences of the ancient tree felling work steps are highly unusual; sometimes the burnt timber at one end of the

* Corresponding author. 
archaeological wooden object may refer to the use of fire during the felling process (Coles, 2006). For these reasons, the experimental studies can offer additional information about the prehistoric tree felling and wood chopping techniques. For example, a case study showed that independently from the tree diameter values, the tree felling efficiency of bronze axes was always almost the same as the steel axes. On the other hand, the stone axes have become more and more useless after the increase of the tree diameter. A further interesting result proved the significance of the handle or haft as the long-hafted axes had greater productivity over time during the experimental tree felling work steps (Mathieu et al., 1997). In addition, the handle's mounting angle of a hand tool can also influence the woodworking efficiency as an approximately $13 \%$ smaller mounting position has produced around $40 \%$ less wood trimming volume within the same time sequence during an archaeological experiment (Kovács et al., 2013). In the beginning of the 1970 's, a research group investigated the ancient wood chopping work steps and the results revealed that a stone axe must have been utilised over six times as long as a steel axe for the accomplishment of the same working tasks (Saraydar et al., 1971).

Finally, within the research scope of the ICH documentation, the main disadvantages of this type of tangible evidences must be mentioned. The potential use-wear marks of metal hand tools can only represent some general intangible information such as the level of usage or the technological aspect of these artefacts. Furthermore, the results of the experimental archaeological studies with hand tool replicas are mainly influenced by the woodworking skills of the actual executors. For this reason, a further application of these conclusions must be carefully handled as the prehistoric skills and woodworking efficiencies cannot be simulated and captured only by replica-based experiments.

On the other hand, the tool marks on the surface of the wellpreserved wooden finds can describe ancient intangible heritage values as they belong to the tangible traces of the prehistoric woodworking techniques and skills. This second type of tangible evidences has been previously investigated only in limited cases since the ancient wooden archaeological objects are relatively rare due to the short lifespans of the early timber constructions. One of these most spectacular sites is the Flag Fen Basin, a Bronze Age wooden causeway at the city of Peterborough in the United Kingdom. Around 170 tool marks were analysed at this site and as a result, the cutting edge width and curvature parameters indicated that only one axe type was used for the construction works at the site. This fact might suggest that the hand tools with broader cutting edges were primarily mounted as a modern billhook implement and were utilised for coppicing works at Flag Fen Basin (Taylor, 2001). Similar tool mark researches were carried out at the Oakbank Crannog, which is located at Loch Tay in the United Kingdom. Crannog is a packwerk-type structure, an artificial wooden island that was used to extend a natural island or a lake site. Altogether 55 well-preserved timber piles and their tool marks were analysed at this Late Bronze Age construction. Based on these hand tool impressions, minimum five axes were applied during the complete carpentry works. Furthermore, this study suggest that the majority of the work was done close to the felling place as the small amount of woodchips founds on the site could only be related to some last minute pile sharpening work steps (Sands 1997). In the conclusion part of this comparison workflow were also mentioned some ideas for the further improvements of similar researches. For example, the reproduction of test tool marks should be executed during welldocumented archaeological experiments. In addition, the survey of hand tool replicas and the spatial analysis of their tool marks should be implemented at the same time within these controlled programs.

For this reason, the impact angles of hand tool strikes and the slope attributes of their test tool marks were precisely recorded by close-range stereo-photogrammetry measurements and shortrange laser scanning techniques in another case study. These results showed the positive correlation between these spatial parameters during the scientific experiment and finally the possible impact angles and the trajectories of unknown hand tool movements could be interpreted by these calculations as well (Kovács et al., 2014).

As a conclusion, the better understanding of prehistoric woodworking techniques and skills can be achieved only by the combination of these previously mentioned workflows. The both type tangible evidences, the hand tool finds and the wooden artefacts must be investigated at the same time by welldesigned archaeological experiments and by objective, repeatable spatial analysis methods. In this condition, the forgotten intangible heritage values can be recovered and used for further archaeological interpretations.

\section{MATERIALS AND METHODS}

One of the most significant Bronze Age copper-ore deposits is located in Mitterberg (Salzburg, Austria). In 2008 and 2009, the excavations at his region have uncovered an area of wet beneficiation and an ore-washery where a well-preserved wooden construction was also found that once had used as a sluice box for washing the grinded ores and for concentrating them. Dendrochronological-based studies have revealed that this sluice box was constructed in 14th century BC (Stöllner et al., 2012). At first, the tangible evidences, the exact position of the timber boards and their tool marks were surveyed in 2009 and 2010 .

\subsection{Laser Scanning and Photogrammetric Documentation of the Sluice Box}

At this excavation site, the in-situ data collection was accomplished with a Trimble GX $3 \mathrm{D} \otimes$ terrestrial laser scanner and with a Nikon D200® calibrated digital camera. Before the beginning of the archaeological conservation work steps, a short-range laser scanning campaign was organised with a FARO ScanArm ${ }^{\circledR}$ survey instrument due to an all-round data acquisition for a detailed digital model. After the combination of these different datasets, the photo-realistic texturing of this approximately $1.5 \mathrm{~m} \times 1.5 \mathrm{~m}$ wide and $0.5 \mathrm{~m}$ high archaeological find could be achieved (Figure 1).

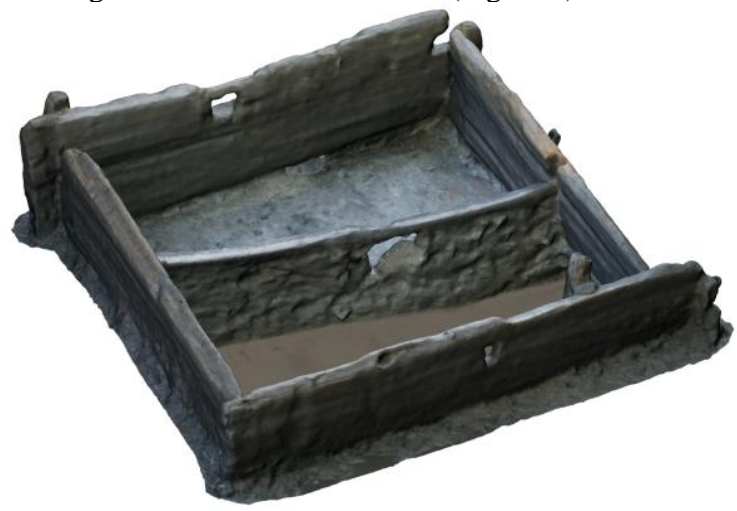

Figure 1. The photo-realistic 3D model of the Bronze Age sluice box 
Furthermore, the virtual reconstruction of the thirty-one wooden objects could be realised during this data processing workflow (Figure 2). Finally, these first results were prepared for the further prehistoric woodworking investigations as the timbering properties of this Bronze Age construction could be visualised after the virtual reconstruction and the tool marks of the wooden objects have been precisely documented by $0.2 \mathrm{~mm}$ spatial resolution during the short-range laser scanning survey (Kovács et al., 2012).

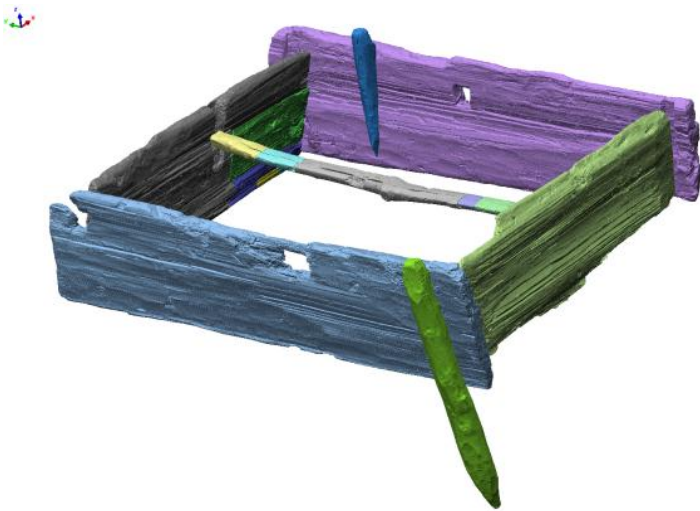

Figure 2. Visualisation of the timbering properties by the virtual reconstruction of the wooden object

\subsection{Laser Scanning Documentation of Hand Tool Replicas and their Test Tool Marks}

In 2013, three different Bronze Age adze replicas and their tool marks were scanned with a DAVID ${ }^{\circledR}$ structured light scanning system. Within this experimental archaeological project, the spatial resolution of this scanning system setup was about 0.4 $\mathrm{mm}$. Altogether 30 facets were used for the 3D analysis and correlation processes. A facet defines a single hand tool impression in the field of tool mark studies.

The aim of this additional data collection can be summarised as follows: The fine morphological characteristics of the tool marks are strongly dependent on the geometry attributes of the hand tools. For this reason, test tool marks were created by known hand tool replicas for an enhanced geometry estimation of the unknown Bronze Age hand tools in the case of the sluice box. The surface of these Bronze Age wooden boards were shaped by similar adzes, therefore a further experiment was also designed for the better understanding of the prehistoric wood trimming procedures.

\subsection{Laser Scanning and Photogrammetric Documentation of an Experimental Wood Trimming Process}

Not only the geometry properties of the hand tools can be calculated by the tool marks, but also the impact angles of adze strikes should be recognised by the fine morphological parameters of the facets (Figure 3).

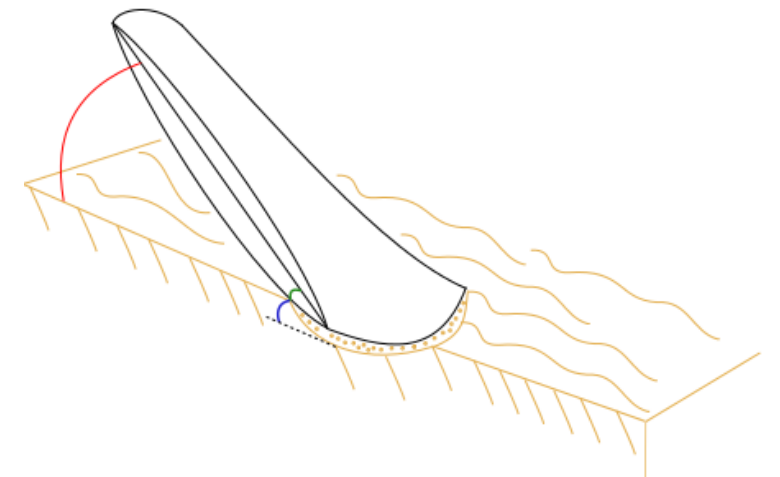

Figure 3. Schematic visualisation of the proposed impact angle analysis - Blue arc: Facet slope, Green arc: Replica head's slope, Red arc: Impact angle

Based on this idea, two identical Nikon D7000® calibrated digital cameras were utilised for the video recording of the hand tool strikes within this experimental wood trimming project. Altogether 20 sliding tool marks were shaped by a Bronze Age replica on eight $10 \mathrm{~cm} \times 60 \mathrm{~cm}$ timber surfaces. The created test tool marks were also documented by $0.4 \mathrm{~mm}$ spatial resolution during the structured light scanning survey. Finally, the trajectories of hand tool movements and the impact angles of adze strikes could be interpreted by these measurements.

\subsection{Application of Well-Documented Bronze Age Hand Tools for an Improved Geometry Estimation}

Unfortunately, Bronze Age axes or adzes have not been found at this prehistoric ore-washery site during the archaeological excavations in 2008 and 2009. For this reason, the straight spatial correlation between the two types of tangible evidences, Bronze Age hand tools and well-preserved tool marks, could not be accomplished in this case study.

On the other hand, six potential hand tools have already been discovered in this region (Mitterberg, Salzburg, Austria) from the same time period (Mayer 1977). The accurate technical drawings of these six artefacts were examined with archaeological scientists and this information was also applied to estimate morphological characteristics of the unknown adze tools in the case of the sluice box.

To summarize, altogether 10 different adze forms (six technical drawings, three replicas from the experimental test tool mark study, one replica from the experimental wood trimming study), 37 selected facets from the both experimental studies and 28 selected sliding tool marks on the surface of the Bronze Age sluice box were investigated in this workflow after the data acquisition.

\subsection{Spatial Analysis Techniques for Tool Mark Studies}

Based on the hand tool impressions of the Bronze Age timber boards, an automatic tool mark recognition and segmentation workflow was designed in a two-and-a-half-dimensional (2.5D) Geographic Information System (GIS) environment (Figure 4). The main idea of this concept can be summarised as follows: The edge lines of the sliding tool marks can be interpreted as the boundaries of key "watersheds" and the smaller catchments within these sliding hand tool impressions can represent the facets. 


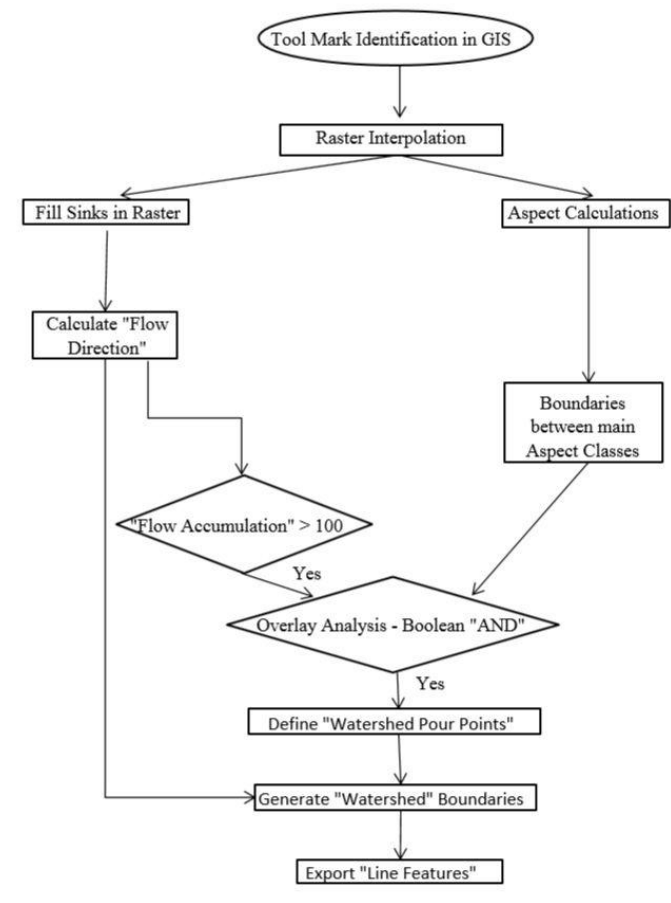

Figure 4. The work steps of the automatic tool mark recognition in GIS environment

The basic overview of these work steps: After the raster interpolation of the imported XYZ coordinates, several hydrologic characteristics such as "Flow Accumulation" and "Flow Direction" parameters of the hand tool impressions were calculated in ArcGIS ${ }^{\circledR}$ Software. The pour points of the catchments were precisely defined by the combination of the calculated stream network and the boundaries between the main aspect classes of the surface model. Finally, the watersheds were identified by the "Flow Direction" characteristics and by the pour point positions (Kovács et al., 2013).

The aspect calculations were used to help the identification process of the watershed pour points. In most cases, the edge lines of the sliding tool marks are running parallel on the object surfaces. For this reason, the direction of these edge lines implied the main categories during the definition of aspect classes. The boundaries of aspect changes between these main categories can represent the edges of hand tool impressions and after the intersections with the stream network, the locations of the pour points could be determined (Kovács et al., 2013).

This objective, repeatable method determines the one of the core parts of this study since this user-independent exact segmentation process provides the initial situation for the detailed morphological characterisation and classification. For this reason, the results of this proposed GIS-based tool mark segmentations were compared with predefined signal processing and peak detection techniques as the cross-sections of the object surfaces can be considered like signal patterns. Finally, a perfect positive correlation was observed between these two methods (Kovács et al., 2014).

After the tool mark segmentation, several parameters such as the aspect, the slope, the length, the width, the depth, the curvature index, the potential impact angle were calculated and compared in this research.

\section{RESULTS}

The prehistoric carpentry skills were interpreted from these calculated geometry parameters. Generally, the intangible heritage cannot be quantified and the measurements of these values are usually based on subjective criteria. The critical assessments of modern woodworking are concluded by the combination of the following factors: required time, mechanical skills, critical thinking skills and math skills of the actual executor. Therefore, these factors were investigated in the case of the Bronze Age sluice box.

\subsection{Parametrisation of Ancient Woodworking Efficiency}

The effectiveness of timberwork can be evaluated by the required time factor. During the test tool mark studies with the three Bronze Age adze replicas, the results showed that the trimming characteristics within the same time sequence are significantly dependent on the width parameter of the cutting edge and the handle's mounting angle (Table 1).

\begin{tabular}{|c|c|c|c|}
\hline & Hand Tool Nr.1 & Hand Tool Nr.2 & Hand Tool Nr.3 \\
\hline $\begin{array}{c}\text { Number of the } \\
\text { Investigated Test Tool } \\
\text { Marks }\end{array}$ & 10 & 10 & 10 \\
\hline $\begin{array}{c}\text { Width of the Cutting } \\
\text { Edge }\end{array}$ & $41 \mathrm{~mm}$ & $46 \mathrm{~mm}$ & $104 \mathrm{~mm}$ \\
\hline $\begin{array}{c}\text { Depth of the Cutting } \\
\text { Edge }\end{array}$ & $8.1 \mathrm{~mm}$ & $10.7 \mathrm{~mm}$ & $11.8 \mathrm{~mm}$ \\
\hline $\begin{array}{l}\text { Hand Tool' Curvature } \\
\text { Index (Depth/Width } \times \\
100)\end{array}$ & 19.76 & 23.26 & 11.35 \\
\hline $\begin{array}{c}\text { Average Width of the } \\
\text { Test Tool Marks }\end{array}$ & $18.9 \mathrm{~mm}$ & $22.3 \mathrm{~mm}$ & $40.4 \mathrm{~mm}$ \\
\hline $\begin{array}{c}\text { Average Depth of the } \\
\text { Test Tool Marks }\end{array}$ & $0.79 \mathrm{~mm}$ & $0.89 \mathrm{~mm}$ & $0.87 \mathrm{~mm}$ \\
\hline $\begin{array}{c}\text { Average Test Tool } \\
\text { Mark' Curvature Index } \\
(\text { Depth/Width } \times 100)\end{array}$ & 4.08 & 3.93 & 2.28 \\
\hline $\begin{array}{c}\text { Handle's Mounting } \\
\text { Angle } \\
\end{array}$ & $49.3^{\circ}$ & $56.4^{\circ}$ & $54.9^{\circ}$ \\
\hline $\begin{array}{c}\text { Working Time - Test } \\
\text { Tool Marks }\end{array}$ & $30 \mathrm{~s}$ & $41 \mathrm{~s}$ & $34 \mathrm{~s}$ \\
\hline $\begin{array}{c}\text { Processed Area within } \\
10 \mathrm{~s}\end{array}$ & $2621 \mathrm{~mm}^{2}$ & $3225 \mathrm{~mm}^{2}$ & $6737 \mathrm{~mm}^{2}$ \\
\hline $\begin{array}{c}\text { Processed Volume } \\
\text { within } 10 \mathrm{~s}\end{array}$ & $2880 \mathrm{~mm}^{3}$ & $4803 \mathrm{~mm}^{3}$ & $10774 \mathrm{~mm}^{3}$ \\
\hline
\end{tabular}

Table 1. The results of the archaeological experiment

The two main Bronze Age wooden boards with the holes were studied separately as the preliminary investigations suggested that these two objects were shaped by different adzes (Stöllner et al., 2012). The outcome of the GIS-based tool mark segmentation and analysis is presented in the following table:

\begin{tabular}{|c|c|c|}
\hline & Object Nr.1 & Object Nr.2 \\
\hline $\begin{array}{c}\text { Number of the Investigated } \\
\text { Tool Mark' Cross Sections }\end{array}$ & 103 & 131 \\
\hline $\begin{array}{c}\text { Average Width of the Tool } \\
\text { Marks }\end{array}$ & $33.2 \mathrm{~mm}$ & $41.5 \mathrm{~mm}$ \\
\hline $\begin{array}{c}\text { Average Depth of the Tool } \\
\text { Marks }\end{array}$ & $1.7 \mathrm{~mm}$ & $2 \mathrm{~mm}$ \\
\hline $\begin{array}{c}\text { Average Tool Mark' } \\
\text { Curvature Index } \\
\text { (Depth/Width } \times 100)\end{array}$ & 4.95 & 4.84 \\
\hline
\end{tabular}

Table 2. Tool mark properties of the Bronze Age wooden boards 


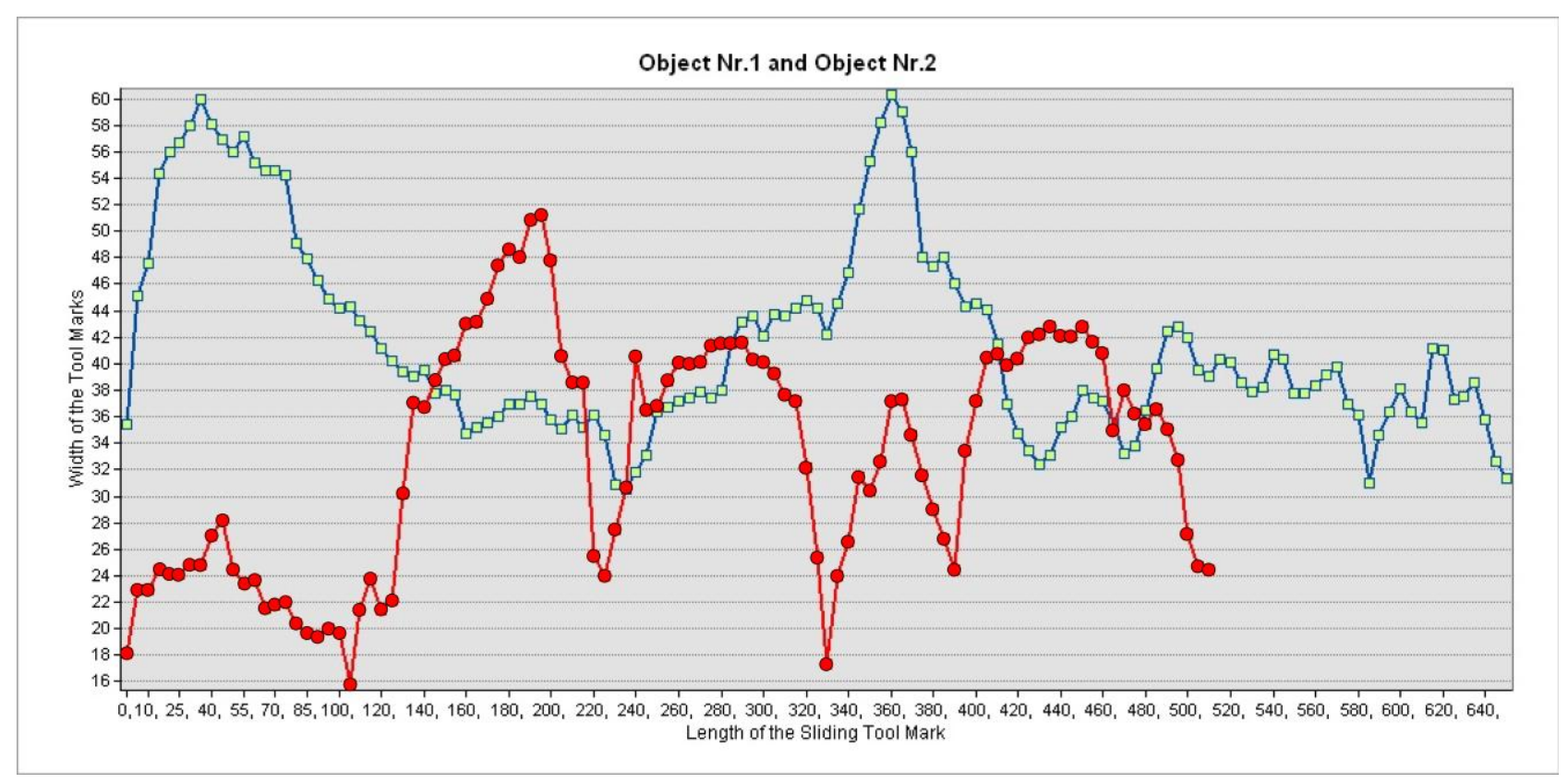

Figure 5. Spatial characterisation of the Bronze Age sliding tool marks - red line with circle markers: Object Nr.1; blue line with square markers: Object Nr.2 (the width and the length parameters are in $\mathrm{mm}$ )

The approximately width values of the unknown cutting edges could be estimated between $70 \mathrm{~mm}$ and $100 \mathrm{~mm}$ by these results. In addition, the depth attributes should be around 20 $\mathrm{mm}$ and these calculations indicated that the hand tool curvature indices should be circa 25 in the both cases. The trimming efficiency of these two unknown adzes could be predicted as well: the trimming area should be approximately $500 \mathrm{~mm}^{2} / \mathrm{s}$ and the trimming volume should be nearly $1200 \mathrm{~mm}^{3} / \mathrm{s}$ by these tools in the hand of an experienced executor.

The patterns of the hand tool impressions are also dissimilar on the surface of the two wooden boards (Figure 5). The Object Nr.1 was only shaped at the border regions as the ancient timber splitting work step produced an asymmetrical wooden board in this case. For this reason, the tool marks are shorter and not too deep and width like in the case of the Object Nr.2. The timber joining accuracy is strongly dependent on the mechanical skills of the carpenters; therefore the border regions of the Object Nr.1 should have been constructed by well-planned hand tool movements. In the central part of the Object Nr.2, the tool marks are sometimes one and a half times wider and two or three times longer, which can imply a trouble-free trimming work.

\subsection{Hand Tool Movement Trajectory Calculations}

The six technical drawings of adze forms and the last replica were utilised for the reconstruction of hand tool movement trajectories. The investigated facet attributes on the surface of the Object Nr.2 suggested the following results: The used Bronze Age adzes could have been mounted at 45-50 degrees and the impact angles of these investigated facets on the wooden board should be between 25-30 degrees.

The Object Nr.1 and the two main timber piles have different tool mark patterns as the most of these tool marks are not running in a parallel structure such as in the case of the Object Nr.2. In the related studies were mentioned that the prehistoric wood sharpening work steps were carried out by axes and not by adzes (Sands 1997). Based on this explanation, hand tool movement trajectory calculations should produce different results in the cases of the Object Nr.1 and the timber piles. The experimental archaeological researches were implemented for trimming work steps and not for sharpening procedures; therefore the trajectory calculations were only conducted in limited cases.

\section{DISCUSSION AND CONCLUSION}

This study represents an objective and repeatable geometrybased timbering analysis workflow. The Bronze Age sluice box was created at least using three different hand tools, two adzes and one axe. The usage of a fourth instrument is also predictable as the regular forms of the timber joining were probably shaped by a chisel implement.

Unfortunately, the prehistoric carpenters mounted the heads of the same Bronze Age tools in several ways (axe, adze or chisel). This fact makes it also difficult to characterise the hand tools and their tool mark geometry parameters. This research showed that a trimming work step produces different patterns from a sharpening work step. In the future, similar archaeological experiments should be documented and surveyed from the treefelling step until the last minute shaping.

On the other hand, the geometry parameters of the applied unknown adzes could be reconstructed which gave us additional information about the possible trimming efficiency. Furthermore, the spatial distribution of the various tool mark impressions indicated the thoughtful timber joining preparations of the ancient carpenters. These skills such as critical thinking or mechanical skills could be "detected" in the case of the sluice box, but the detailed categorisation of these prehistoric intangible values will always be established by subjective criteria. 
This intangible heritage should belong to the "Knowledge and practices concerning nature and the universe" class. However, the combination of several ancient woodworking studies could reveal some common spatial patterns for example in the timber joining work steps. For this reason, the general prehistoric woodworking skills would be labelled as a "Traditional craftsmanship" in an extended research.

The analysis of the Bronze Age sluice box provided significant results primarily in the field of the trimming work step investigation. This methodology could offer a model for the related archaeological studies as the simultaneous documentation of the both tangible evidence types can produce novel intangible heritage interpretation opportunities in the future.

\section{ACKNOWLEDGEMENTS}

The work is generously supported by the Austrian Science Fund (FWF Project F3114) in the framework of the Special Research Program "History of Mining Activities in the Tyrol and Adjacent Areas" (SFB HiMAT) as well as by the Austrian province governments of Tyrol, Vorarlberg and Salzburg, the Autonomous Province Bolzano-South Tyrol, Italy, the local authorities of the mining areas concerned, the TransIDEE foundation and the University of Innsbruck, Austria.

Special thanks to Prof. Thomas Stöllner, Dr. Peter Thomas (Deutsches Bergbaumuseum Bochum) and Mr. Wolfgang Lobisser (VIAS Wien) for the support during the scientific experiment.

\section{REFERENCES}

Coles, J.M., 2006. Ancient wood, woodworking and wooden houses. (Contribution to the ESF Workshop on the Reconstruction of Wooden Buildings from the Prehistoric and Early Historic Period in Århus, Denmark in 1987), euroERA. Journal for (Re)construction and Experiment in Archaelogy. 3, pp. 50-57.

Johann, E. et al., 2012. Europe. in Parrotta, J. A., Trosper, R. L. (Eds.), Traditional Forest-Related Knowledge: Sustaining Communities, Ecosystems and Biocultural Diversity. Springer, Netherlands, pp. 203-249.

Kienlin, T.L., Ottaway, B.S., 1998. Flanged axes of northalpine region: An assessment of the possibilities of use-wear analysis on metal artefacts. in Mordant, C., Perno, M., Rychner, V. (Eds.), L'Atelier du bronzier en Europe du XX au VIII siècle avant notre ère, Paris: Comité des travaux historiques et scientifique, 2, pp: 271-286.

Kovács, K., Hanke, K., 2012. Hydrologic and feature-based surface analysis for tool mark investigation on archaeological finds, In: The International Archives of Photogrammetry, Remote Sensing and Spatial Information Sciences, XXXIX-B5, pp. 565-570.

Kovács, K., Hanke, K., 2013. Automatic tool mark identification and comparison with known Bronze Age hand tool replicas. ISPRS Ann. Photogramm. Remote Sens. Spat. Inf. Sci., 2(5), pp. 181-186.

Kovács, K., Hanke, K., 2014. Interpretation of Hand Tool Movement's Trajectories by Spatial Analysis of Bronze Age Tool Marks. International Journal of Heritage in the Digital Era, 3(1), pp. 83-96.
Mathieu, J.R., Meyer, D.A., 1997. Comparing Axe Heads of Stone, Bronze, and Steel: Studies in Experimental Archaeology. Journal of Field Archaeology, 24(3), pp. 333-351.

Mayer, E.F., 1977. Die Äxte und Beile in Österreich. First Edit., München: Beck.

Roberts, B., Ottaway, B.S., 2003. The use and significance of socketed axes during the Late Bronze Ages. European Journal of Archaeology, 6(2), pp. 119-140.

Sáez, C.G., Lerma, I.M., 2015. Traceology on Metal. Use-Wear Marks on Copper-Based Tools and Weapons. in Marreiros, J.M., Gibaja Bao, J.F., Ferreira Bicho, N. (Eds.), Use-Wear and Residue Analysis in Archaeology. Springer, USA, pp. 171-189.

Sands, R., 1997. Prehistoric Woodworking: The analysis and interpretation of Bronze and Iron Age toolmarks. University College London: Archetype Press.

Saraydar, S., Shimada, I., 1971. A quantitative comparison of efficiency between a stone axe and a steel axe. American Antiquity, 36(2), pp. 216-217.

Scovazzi, T., 2015. Intangible Cultural Heritage as Defined in the 2003 UNESCO Convention. in Golinelli, G. M. (Ed.), Cultural Heritage and Value Creation: Towards New Pathways. Springer, Switzerland, pp. 105-126.

Stefano, M.L., Davis, P., Corsane, G., 2012. Touching the Intangible: An Introduction. in Stefano, M.L., Davis, P., Corsane, G. (Eds.), Safeguarding Intangible Cultural Heritage. Boydell Press, pp. 1-9.

Stöllner, T., Breitenlechner, E., Fritzsch, D., Gontscharov, A., Hanke, K., Kirchner, D., Kovács, K., Moser, M., Nicolussi, K., Oeggl, K., Pichler, T., Pils, R., Prange, M., Thiemeyer, H., and Thomas, P., 2012. Ein Nassaufbereitungskasten vom Troiboden. Interdisziplinäre Erforschung des bronzezeitlichen Montanwesens am Mitterberg (Land Salzburg, Österreich), Jahrbuch des Römisch-Germanischen Zentralmuseums Mainz, 57, pp. 1-32.

Taylor, M., 2001. The wood. in Pryor, F. et al., The Flag Fen Basin: Archaeology and Environment of a Fenland Landscape. English Heritage, UK, pp. 167-228.

Tegel, W., Elburg, R., Hakelberg, D., Stäuble, H., Büntgen, U., 2012. Early Neolithic Water Wells Reveal the World's Oldest Wood Architecture. PLOS ONE, 7(12), pp. 1-8.

UNESCO, 2003. Convention for the Safeguarding of the Intangible Cultural Heritage. Article 2, Paris, France http://www.unesco.org/culture/ich/index.php?pg=00006 (19.03. 2015).

Van de Noort, R., Cumby, B., Blue, L., Harding, A., Hurcombe, L., Hansen, T.M., Wetherelt, A., Wittamore, J., Wyke, A., 2014. Morgawr: an experimental Bronze Age-type sewn-plank craft based on the Ferriby boats. International Journal of Nautical Archaeology, 43(2), pp. 292-313. 